\title{
Preparation and Characterization of Phosphoric Acid-doped Blend Membrane Composed of Sulfonated Poly(arylene ether sulfone) and Polybenzimidazole for Fuel Cell Application
}

\author{
Dong Liu, Manabu Tanaka and Hiroyoshi Kawakami* \\ Department of Applied Chemistry, Tokyo Metropolitan University, \\ Hachioji, Tokyo 192-0397, Japan \\ Tel: +81-426-77-1111, Fax: +81-426-77-2821 \\ E-mail: kawakami-hiroyoshi@tmu.ac.jp
}

\begin{abstract}
A phosphoric acid (PA)-doped blend membrane composed of sulfonated poly(arylene ether sulfone) (SPAES) and polybenzimidazole (PBI) was developed for fuel cell application. Blending of SPAES and PBI improved its dimensional stability and gas barrier properties due to the acid-base interaction. Although the proton conductivity of the blend membrane was lower than that of the pristine SPAES membrane, the PA-doping redeemed its disadvantage to show enough high proton conductivity comparable to the conductivity of the Nafion membrane even at low relative humidity. The novel acid-doped blend membrane has a potential application for future fuel cells.
\end{abstract}

Keywords: fuel cell, proton exchange membrane, polymer blend, proton conductivity, poly(arylene ether sulfone)

\section{Introduction}

Proton exchange membrane (PEM) is one of the key components in polymer electrolyte fuel cell (PEFC) that has advantages on its high energy efficiency and no emissions of pollutants [1]. PEMs are required to show excellent performances, such as high proton conductivity, high membrane stability, and low gas permeability [2-4]. Among them, high proton conductivity, especially at low relative humidity $(\mathrm{RH})$, has been particularly desired for fuel cell vehicle application to operate in varied circumstances even without any external humidification system.

Perfluorosulfonic acid (PFSA) aliphatic polymers, such as Nafion ${ }^{\circledR}$ (Du Pont), have been widely utilized as PEMs because of their good proton conductivity and chemical stability. On the other hand, aromatic hydrocarbon polymer electrolyte membranes have also been actively developed as alternatives for the conventional PFSA membranes. These aromatic hydrocarbon polymers including sulfonated polyimide (SPIs) [5-7], sulfonated poly(arylene ether sulfone)s (SPAESs) [8,9], and sulfonated polyphenylenes (SPPs) [10] have advantages in their low environmental load and low production cost as well as their high thermal and mechanical stabilities. However, these membranes often lead the drastical proton conductivity drop under low humidity or dry conditions due to desorption of water from the membranes.

Recently, we have developed a new type of PEMs that were composed of phosphoric acid (PA), polybenzimidazole (PBI), and SPIs $[11,12]$. One of the PA-doped SPI/PBI blend membranes, PA(120)-SPI(90)/PBI(10) where the numbers in brackets represent weight ratios of PA, SPI, and PBI in the membrane, showed extremely high proton conductivity $\left(0.13 \mathrm{~S} / \mathrm{cm}\right.$ at $90^{\circ} \mathrm{C}$ and $30 \% \mathrm{RH})$, which was approximately two orders of magnitude superior to that of Nafion 117 membrane under the same condition [11]. In the 
previous study, we revealed that the PA-SPI/PBI membrane provided a new proton transport pathway between phosphoric acid and sulfonic acid groups in addition to the conventional proton hopping among phosphoric acid groups at low humidity [11,12]. The PA-PBI/SPI membrane maintained its proton conductivity of above $10^{-2}$ $\mathrm{S} / \mathrm{cm}$ at $120^{\circ} \mathrm{C}$ and $0 \% \mathrm{RH}$ after 1000 hours of operation. However, SPIs themselves have disadvantages on their low hydrolysis and oxidative stability as well as low proton conductivity at low relative humidity.

In this study, the acid-doped blend system was applied to another polymer electrolyte. We focused on SPAESs that have been actively developed for PEMs because of their higher chemical stability and higher proton conductivity under low relative humidity conditions than SPIs. This paper reports preparation and characterization of a PA-doped SPAES/PBI blend membrane. Advantageous effects of blending of SPAES and PBI were evaluated on its gas barrier and mechanical properties by comparing with the pristine SPAES and Nafion membranes. Finally, proton conductivity of the PA-SPAES/PBI was examined for future fuel cell application.

\section{Experimental}

\subsection{Materials}

Bis(4-fluorophenyl) sulfone (FPS) and 4,4'biphenol (BP) were purchased from TCI Co. Ltd (Tokyo, Japan), and were dried under vacuum at $80^{\circ} \mathrm{C}$ before use. 3,3-Diaminobenzidine (DAB), 4,4-oxybisbenzoic acid (OBBA), and phosphorus pentoxide were purchased from Sigma-Aldrich Co. (St Louis, MO, USA) and were used after drying under vacuum at $80^{\circ} \mathrm{C}$ overnight. Fuming sulfuric acid $(30 \%)$ was obtained from Wako Pure Chemical Industries Co. (Tokyo, Japan). All other chemicals were purchased from Kanto Chemical Co. (Tokyo, Japan) and were used as received. 3,3'-Disulfonate-4,4'-difluorodiphenyl sulfone (SFDPS) sodium salt was synthesized as reported previously [8,9]. Nafion 117 (Du Pont Co. Ltd, Tokyo, Japan) was used as the control membrane.

\subsection{Synthesis of SPAES}

SPAES was synthesized by reference to previous papers $[8,9]$. A $50 \mathrm{~mL}$ three-neck round-bottomed flask was charged with SFDPS (1.430 g, 3.120 $\mathrm{mmol})$, FPS (0.340 g, $1.337 \mathrm{mmol})$, BP $(0.830 \mathrm{~g}$, $4.457 \mathrm{mmol})$, and potassium carbonate $(1.905 \mathrm{~g}$, $13.78 \mathrm{mmol})$. The reaction was carried out in 15 $\mathrm{mL}$ anhydrous $\mathrm{N}, \mathrm{N}$-dimethylacetamide (DMAc) and $3 \mathrm{~mL}$ toluene with a Dean-Stark trap. The reaction was maintained at $130^{\circ} \mathrm{C}$ for $3 \mathrm{~h}$ before the Dean-Stark trap was removed. Then, the temperature was elevated to $170^{\circ} \mathrm{C}$. The reaction was continued for $3 \mathrm{~h}$ and light yellow viscous mixture was obtained. About $15 \mathrm{~mL}$ of DMAc was added to the mixture solution, which was poured into a large excess of hot water. The obtained polymer was washed with deionized water and methanol several times. After collecting with glass filter (G2), the obtained white polymer was dried under vacuum at $100^{\circ} \mathrm{C}$.

\subsection{Synthesis of PBI}

PBI was synthesized according to our previous paper [11]. In a three-necked flask, methanesulfonic acid (40 g) and phosphorus pentoxide $(4.0 \mathrm{~g})$ were charged and stirred at $100^{\circ} \mathrm{C}$ under nitrogen. DAB $(2.000 \mathrm{~g}, 0.9334$ mmol) and OBBA (2.410 g, $0.9334 \mathrm{mmol})$ were added to the flask, and mechanically stirred at $110^{\circ} \mathrm{C}$ for $5 \mathrm{~h}$ and at $140^{\circ} \mathrm{C}$ for $12 \mathrm{~h}$. After the reaction, the solution was slowly poured into deionized water to precipitate the polymer by adding sodium hydroxide. After washing with deionized water several times, PBI was collected and dried in a vacuum oven at $100^{\circ} \mathrm{C}$ for $10 \mathrm{~h}$.

\subsection{Preparation of PA-SPAES/PBI membrane}

The SPAES/PBI blend membrane was prepared using a solvent casting method. The blend ratio was set to be $90 \mathrm{wt} \%$ of SPAES and $10 \mathrm{wt} \%$ of PBI. A dimethylsulfoxide (DMSO) mixture solution of SPAES and PBI was cast on a glass plate, and the plate was then placed in a vacuum oven at $110{ }^{\circ} \mathrm{C}$ for $24 \mathrm{~h}$. The membranes were immersed in ethanol and deionized water for $4 \mathrm{~h}$ each. The resulting membranes were dried in a vacuum oven at $80^{\circ} \mathrm{C}$ for $24 \mathrm{~h}$. The thicknesses of all of the membranes were approximately $30 \mu \mathrm{m}$. The blend membrane, SPAES/PBI, was then immersed into an $85 \mathrm{wt} \%$ PA aqueous solution for an appropriate time to yield the PA-SPAES/PBI membrane.

\subsection{Characterization}

The structures of the obtained SPAES and PBI were characterized by ${ }^{1} \mathrm{H}-\mathrm{NMR}$ (Avance 500, Bruker, Karlsruhe, Germany). The molecular weights $\left(M_{\mathrm{w}}\right.$ and $\left.M_{\mathrm{n}}\right)$ of SPAES and PBI were determined by gel permeation chromatography (detector: RI-2031, JASCO, Tokyo, Japan) using two Shodex SB-806HQ and SB-804 HQ columns. Dimethylformamide containing $0.01 \mathrm{M}$ lithium bromide was used as the eluent at a flow rate of 1.0 $\mathrm{ml} \mathrm{min}{ }^{-1}$. The molecular weights were estimated by 
comparing the retention times on the columns to those of standard polystyrene. Ion exchange capacity (IEC) of the blend membranes was determined by titration. In the titration method, a piece of membrane samples was equilibrated in large excess of a $0.1 \mathrm{M} \mathrm{NaCl}$ aqueous solution at $40^{\circ} \mathrm{C}$ for one day. The amount of $\mathrm{HCl}$ released from the membrane samples was measured by titration with a $0.01 \mathrm{~N} \mathrm{NaOH}$ aqueous solution.

Water uptake of the membranes was gravimetrically measured from the dried and humidified membranes. The membranes were dried in a vacuum oven at $80^{\circ} \mathrm{C}$ for $10 \mathrm{~h}$ and then immersed in liquid water at $80^{\circ} \mathrm{C}$. After $4 \mathrm{~h}$, the membrane was then wiped dry and quickly weighed. The water uptake was calculated using Eq. (1):

$$
W_{\mathrm{H}_{2} \mathrm{O}}(\%)=\frac{W_{s}-W_{d}}{W_{d}} \times 100
$$

where $W_{\mathrm{s}}$ and $W_{\mathrm{d}}$ are the weights of the wet (in water at $80^{\circ} \mathrm{C}$ for $5 \mathrm{~h}$ ) and dry membranes, respectively. The swelling ratio (thickness change) was similarly calculated using Eq. (2):

$$
T_{\mathrm{H}_{2} \mathrm{O}}(\%)=\frac{T_{s}-T_{d}}{T_{d}} \times 100
$$

where $T_{\mathrm{s}}$ and $T_{\mathrm{d}}$ are the thickness of the wet (in water at $80^{\circ} \mathrm{C}$ for $5 \mathrm{~h}$ ) and dry membranes, respectively.

The oxygen gas permeability were measured with a high vacuum apparatus (K-315-H, Rika Seiki, Inc., Tokyo, Japan). The gas permeation measurements of the membranes were carried out at $35^{\circ} \mathrm{C}$ and $76 \mathrm{cmHg}$. The tensile test was performed by a precision universal tester (AGS-X5kN, Shimadzu Co., Tokyo, Japan) at $27^{\circ} \mathrm{C}$ and $60 \% \mathrm{RH}$. The membranes were cut into rectangle shapes $(10 \mathrm{~mm} \times 40 \mathrm{~mm})$ and set on the fixtures with $20 \mathrm{~mm}$ gap. The stress-strain tests were performed at a controlled velocity of $1 \mathrm{~mm}$ $\min ^{-1}$ until breaking.

The amounts of phosphoric acid doping in the blend membranes were calculated from Eq. (3):

$$
W_{P A}(\%)=\frac{W_{d o p}-W_{d}}{W_{d}} \times 100
$$

where $W_{\text {dop }}$ and $W_{\mathrm{d}}$ are the weights of the doped and dried membranes, respectively.

Proton conductivity of the membranes were measured using electrochemical impedance spectroscopy over the frequency range from $50 \mathrm{~Hz}$ to $500 \mathrm{kHz}$ (Hioki 3532-50, Tokyo, Japan) as reported in previous papers $[5,7]$. The membranes $\left(1.0 \times 4.0 \mathrm{~cm}^{2}\right)$ and two blackened platinum plate electrodes were placed in a Teflon cell. The distance between the two electrodes was $1.0 \mathrm{~cm}$. The cell was placed in a thermo-controlled humidity chamber to measure the temperature and relative humidity dependence on the proton conductivity.

\section{Results and discussion}

\subsection{Synthesis of SPAES and PBI}

SPAES (SFDPS:FPS=7:3) were designed in consideration of its theoretical IEC $(2.73 \mathrm{meq} / \mathrm{g})$ and water insolubility, and was synthesized by nucleophilic substitution polycondensation (Scheme 1(a)). The ${ }^{1}$ H-NMR spectroscopy revealed successful synthesis of SPAES with maintaining the feeding monomer ratio. The molecular weight and polydispersity of SPAES were $M_{\mathrm{w}}=3.5 \times 10^{5}$ and $M_{\mathrm{w}} / M_{\mathrm{n}}=2.1$, respectively, by the GPC measurement. PBI was also obtained according to our previous study (Scheme 1(b)) [11]. The molecular weight and polydispersity of the obtained PBI were $M_{\mathrm{w}}=1.1 \times 10^{5}$ and $M_{\mathrm{w}} / M_{\mathrm{n}}=3.2$, respectively. Both two polymers had enough high molecular weight to form tough membranes and showed good solubility in polar aprotic solvents, such as DMF and DMSO.

(a)

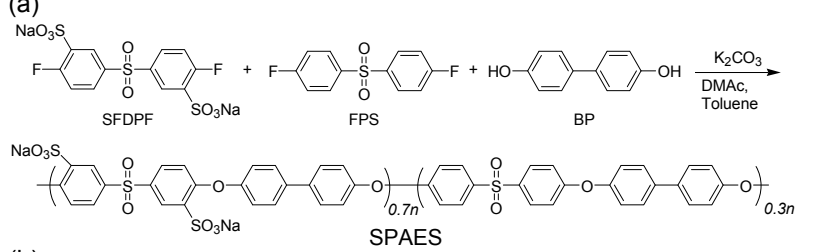

(b)

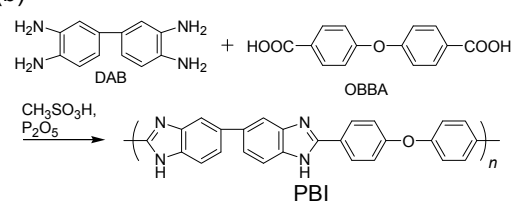

Scheme 1. Synthesis of (a) SPAES and (b) PBI.

Table 1. Composition and IEC values of the SPAES, SPAES/PBI blend, PA-doped SPAES/PBI, and Nafion 117 membranes.

\begin{tabular}{cccc}
\hline Membrane & $\begin{array}{c}\text { SPAES:PBI } \\
(\mathrm{wt} \% / \mathrm{wt} \%)\end{array}$ & $\begin{array}{c}\text { PA contents } \\
(\mathrm{wt} \%)\end{array}$ & $\begin{array}{c}\text { IEC } \\
(\mathrm{meq} / \mathrm{g})\end{array}$ \\
\hline SPAES & $100: 0$ & - & 2.46 \\
SPAES/PBI & $90: 10$ & - & 2.21 \\
PA-SPAES/PBI & $90: 10$ & 47 & - \\
Nafion 117 & - & - & 0.89 \\
\hline
\end{tabular}

Appropriate amounts of SPAES and PBI were separately dissolved in DMSO, and each polymer solution was respectively casted in petri dishes to obtain SPAES and PBI membranes. The thicknesses of the membranes were both $c a .30 \mu \mathrm{m}$. The SPAES membrane was treated with $1 \mathrm{M} \mathrm{HCl}$ 
aq. to give a proton from for characterizations. The IEC value of SPAES was estimated to be 2.46 $\mathrm{meq} / \mathrm{g}$, which was close to the theoretical value (2.73 meq $/ \mathrm{g})$ (Table 1).

3.2 Preparation and characterizations of the SPAES/PBI blend membrane

A SPAES/PBI blend membrane was prepared using a solvent cast method. The blend ratio of SPAES and PBI was fixed to SPAES : PBI = $90 \mathrm{wt} \%: 10 \mathrm{wt} \%$ based on our previous study on the SPI/PBI blend membranes [11]. The experimentally given IEC values of the blend membrane $(2.21 \mathrm{meq} / \mathrm{g})$ was slightly lower than the theoretical value $(2.46 \mathrm{meq} / \mathrm{g})$, indicating the existence of acid-base interaction between sulfonic acid groups in SPAES and basic moieties of PBI.

The acid-base interaction in the blend membranes was also confirmed by the water uptake and swelling ratio results (Table 2). The water uptake and swelling ratio of the SPAES/PBI blend membrane were both much lower than those of the SPAES membrane. Such relatively low water uptake and swelling ratio are favorable for PEMs because excessive water uptake and swelling often lead rapid degradation of the membrane by humidity change during fuel cell operation.

Gas barrier property is one of the important factors for PEMs. Gas crossover through PEMs has several disadvantages including fuel efficiency reduction, cell potential depression, and the formation of reactive oxygen species, which will degrade membrane and catalyst in the fuel cells. Therefore, lower gas permeability is strongly desired for PEMs. Table 2 summarizes oxygen gas permeability of the membranes. The SPAES/PBI blend membrane showed lower gas permeability coefficient $\left(P_{\mathrm{O} 2}\right)$ than the pristine SPAES membrane due to its lower gas diffusivity $\left(D_{\mathrm{O} 2}\right)$ and solubility $\left(S_{\mathrm{O} 2}\right)$. It is considered that the low gas permeable PBI component and acid-base interaction in the blend membrane prevented oxygen gas dissolution and diffusion.

Table 2. Water uptake, swelling ratio, and oxygen permeability of the SPAES, SPAES/PBI blend, and Nafion 117 membranes.

\begin{tabular}{cccccc}
\hline Membrane & $W_{\mathrm{H}^{2} \mathrm{O}}(\mathrm{wt} \%)^{\mathrm{a})}$ & $\left.T_{\mathrm{H}^{2} \mathrm{O}}(\%)\right)^{\mathrm{b})}$ & $\mathrm{PO}_{2}{ }^{\mathrm{c})}$ & $\mathrm{DO}_{2}{ }^{\mathrm{c})}$ & $\mathrm{SO}_{2}{ }^{\mathrm{c}}$ \\
\hline SPAES & 156 & 40 & 2.3 & 0.67 & 3.48 \\
SPAES/PBI & 37 & 11 & 0.64 & 0.38 & 1.70 \\
Nafion 117 & 16 & 7.7 & 1.1 & 4.6 & 0.23 \\
\hline
\end{tabular}

a) $W_{\mathrm{H} 2 \mathrm{O}}$ : Water uptake when the membrane soaked in hot water at $80^{\circ} \mathrm{C}$. b) $T_{\mathrm{H} 2 \mathrm{O}}$ : Swelling ratio (thickness change) when the membrane soaked in hot water at $80^{\circ} \mathrm{C}$. c) $P_{\mathrm{O}_{2}}$ : Oxygen permeability coefficient $\left(\times 10^{-10} \mathrm{~cm}^{3}\right.$ (STP) $\mathrm{cm} /\left(\mathrm{cm}^{2} \mathrm{sec}\right.$ $\mathrm{mmHg}), D_{\mathrm{O}_{2}}$ : Oxygen diffusivity coefficient $\left(\times 10^{-8} \mathrm{~cm}^{2} / \mathrm{sec}\right)$, and $S_{\mathrm{O}_{2}}$ : oxygen solubility coefficient $\left(\times 10^{-2} \mathrm{~cm}^{3}(\mathrm{STP}) /\left(\mathrm{cm}^{3} \mathrm{mmHg}\right)\right.$ at $35^{\circ} \mathrm{C}$ and $76 \mathrm{cmHg}$.
Mechanical properties of the membranes were evaluated by a tensile test. Stress-strain curves in Figure 1 clearly demonstrated that the blend membrane had better mechanical properties than the pristine SPAES and Nafion 117 membranes. Maximum strength, maximum strain, and Young's modulus of the SPAES/PBI blend membrane were $64 \mathrm{MPa}, 53 \%$, and $1.3 \mathrm{GPa}$, respectively. These values are superior to those of SPAES and Nafion 117 membranes (Young's moduli $=0.92 \mathrm{GPa}$ and 4.2 $\mathrm{MPa}$, respectively). Such high elastic modulus and moderate stretch of the SPAES/PBI blend membrane are suitable for fuel cell application.

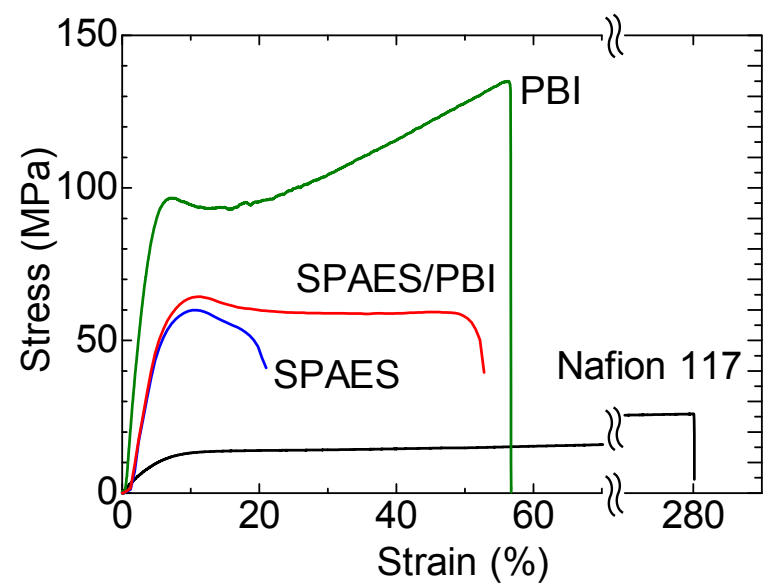

Figure 1. Stress-strain curves of SPAES, PBI, SPAES/PBI, and Nafion 117 membranes at $27^{\circ} \mathrm{C}$ and $60 \%$ RH.

3.3 Preparation and proton conductivity of the PA-SPAES/PBI membrane

A PA-SPAES/PBI membrane was obtained by immersing the SPAES/PBI blend membrane in an $85 \%$ PA aqueous solution. The PA doping level (PA contents) was estimated to be $47 \mathrm{wt} \%$ by the weight change of the SPAES/PBI blend membrane before and after doping. The PA content was much lower than the conventional PA-PBI membranes ( $>$ $200 \mathrm{wt}^{\mathrm{t}} \%$ ) [13]. However, we have revealed that such low PA contents were even useful for the improvement of proton conductivity in the PA-SPI/PBI membranes [11].

The proton conductivity of the SPAES, SPAES/PBI blend, and PA-SPAES/PBI membranes were measured by electrochemical impedance spectroscopy. The temperature dependence on the proton conductivity of the membranes under a high relative humidity condition is shown in Figure 2(a). The proton conductivity of SPAES/PBI membrane was lower than that of the Nafion 117 membrane. On the other hand, the PA-doped blend membrane showed higher proton conductivity than the Nafion 117 membrane at all temperatures. For example, 
the conductivity of PA-SPAES/PBI membrane at 90 and $30{ }^{\circ} \mathrm{C}(98 \% \mathrm{RH})$ were 0.25 and $0.079 \mathrm{~S} / \mathrm{cm}$, respectively, which were both almost twice higher than that of the Nafion 117 membrane. The reason why the PA-doped blend membranes had higher conductivity than the Nafion 117 membrane is considered to be derived from the facile proton transport in the presence of water and phosphoric acid in the membranes.

Figure 2(b) depicts the humidity dependence on the proton conductivity of the membranes at $90{ }^{\circ} \mathrm{C}$. It is known that the proton conductivity of most aromatic hydrocarbon polymer electrolyte membranes has a stronger tendency to relative humidity than the Nafion membrane. The pristine SPAES showed relatively high proton conductivity even at low humidity due to its high IEC values and subsequent high water uptake (Table 1). However, as mentioned above, such excessive water uptake and swelling lead impractical membrane stability for fuel cell applications. Blending of PBI could suppress excessive water uptake, but the SPAES/PBI blend membrane showed low proton conductivity especially under low relative humidity conditions as shown in Figure 2(b). In contrast, the PA-doping to the SPAES/PBI membrane redeemed its disadvantage to show enough high proton conductivity comparable to the conductivity of the Nafion membrane even at low relative humidity. Such high proton conductivity of the PA-SPAES/PBI membrane may be attributed from the new proton transport pathway between phosphoric acid and sulfonic acid groups in addition to the conventional pathway among sulfonic acid groups via water. Details of the novel proton transport mechanism in PA-doped blend membranes were discussed in our previous papers $[11,12]$.

\section{Conclusion}

The novel PA-doped SPAES/PBI blend membrane was prepared and characterized for fuel cells. The precursor SPAES/PBI membrane showed higher dimensional stability, better gas barrier property, and higher mechanical strength than the pristine SPAES membrane due to the acid-base interaction. Although the proton conductivity of the blend membrane was lower than that of the pristine SPAES membrane, the PA-doping improved the proton conductivity close to the conductivity of the Nafion membrane even at low relative humidity. It is considered that new proton transport pathway between phosphoric acid and sulfonic acid groups could be formed in the membrane. The novel acid-doped blend membrane has a potential application for future fuel cell application.

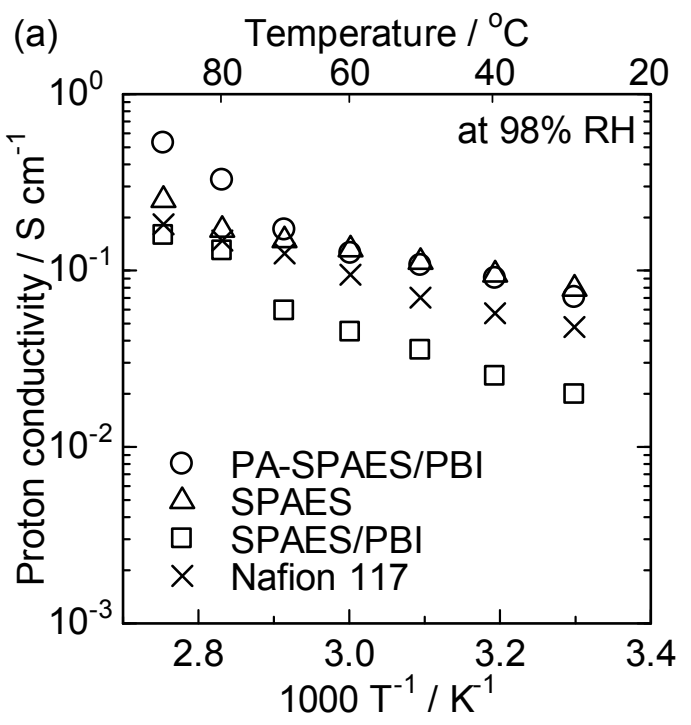

(b)

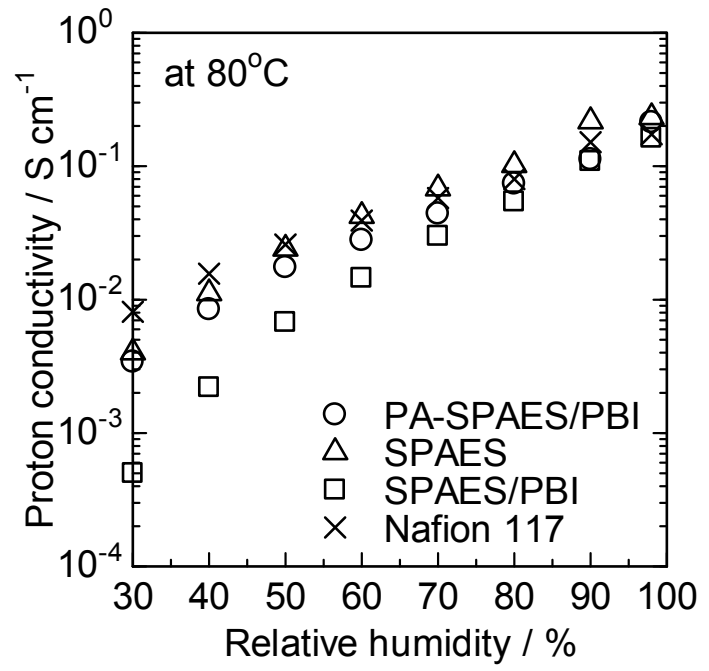

Figure 2. (a) Temperature and (b) relative humidity dependence on proton conductivity of the PA-SPAES/PBI (O), SPAES ( $\triangle$ ), SPAES/PBI (口), and Nafion $117(\times)$ membranes.

\section{Acknowledgements}

This work was partially supported by a Grant from New Energy and Industrial Technology Development Organization (NEDO) and JSPS KAKENHI Grant Number 24750225.

\section{References}

1. W. Vielstich, Handbook of Fuel Cells, Wiley, Chichester, England (2009).

2. M. A. Hickner, B. S. Pivovar, Fuel Cells, 5 (2005), 213.

3. Y. Wang, K. S. Chen, J. Mishler, S. C. Cho, X. C. Adroher, Appl. Energ., 88 (2011), 981. 
4. U. Eberle, B. Müller, R. von Helmolt, Energy Environ. Sci. 5 (2012), 8780.

5. K. Yamazaki, H. Kawakami, Macromolecules, 43 (2010), 7185.

6. J. Saito, M. Tanaka, K. Miyatake, M. Watanabe, J. Polym. Sci. Polym. Chem., 48 (2010), 2846.

7. K. Yamazaki, G. Wang, M. Tanaka, H. Kawakami, J. Power Sources, 216 (2012), 387.

8. F. Wang, M. Hickner, Q. Ji, W. Harison, J. Mecham, T. A. Zawodzinski, J. E. McGrath, Macromol. Symp., 175 (2001), 387.

9. B. Bae, S. Kawamura, K. Miyatake, M.
Watanabe, J. Polym. Sci. Polym. Chem., 49 (2011), 3863.

10. S. Seesukphronrarak, K. Ohira, K. Kidena, N. Takimoto, C. S. Kuroda, A. Ohira, Polymer 51 (2010), 623.

11. K. Suzuki, Y. Iizuka, M. Tanaka, H. Kawakami, J. Mater. Chem., 22 (2012), 23767.

12. Y. Iizuka, M. Tanaka, H. Kawakami, Polym. Int., 62 (2012), 703.

13. Q. Li, J. O. Jensen, R. F. Savinell, N. J. Bjerrum, Prog. Polym. Sci., 34 (2009), 449. 